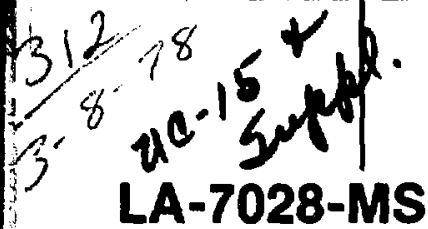

Informal Report

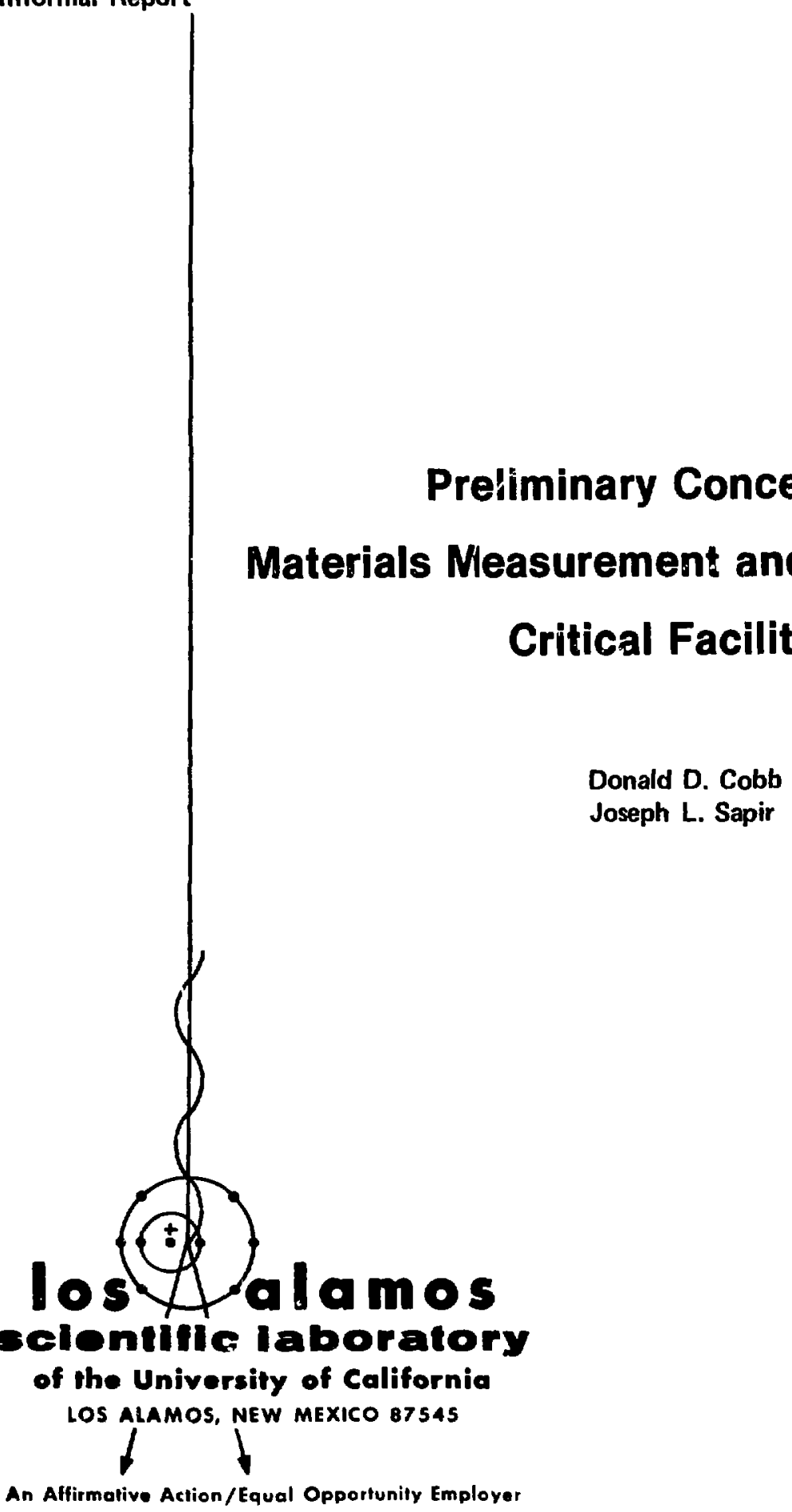

UC-15

Issued: January 1978 
CONTENTS

TABLES. . . . . . . . . . . . . . . . iv FIGURES . . . . . . . . . . . . . . . . . v ABSTRACT. . . . . . . . . . . . . . . 1

I. INTRODUCTION AND SUMMARY. . . . . . . . . . . . l A. Introduction. . . . . . . . . . . . . . . . 1

B. Summary .................. 3

II. MATERIALS MEASUREMENT AND ACCOUNTING SYSTEM . • • 5

A. General Description . . . . . . . . . . 5

B. Improved Materials Accounting . . . . . . 7

C. Diversion Detection . . . . . . . . . . 8

III. MATERIALS ACCOUNTING IN CRITICAL FACILITIES . • . io

A. General Considerations. . . . . . . . 10

B. Material Transfers. . . . . . . . . . 12

C. Inventory Verification. . . . . . . . . . 13

1. Physical Inventory. . . . . . . . . . . 14

2. Timely Verification of Reactor Inventory. - 15

3. Sampling Plans.............. 17

IV. MATERIALS MEASUREMENTS IN CRITICAL FACILITIES • • . 21

A. Integral Reactivity Measurements. . . . . . 23

B. Autoradiography . . . . . . . . . . . . . 30

C. Nondestructive Assay (NDA). . . . . . . . 36

1. Neutron Measurements. . . . . . . . 36

2. Gamma Measurements. . . . . . . . 38

V. CONCEPT DEVELOPMENT: THE SAFEGUARDS STUDY. . . . . 39

A. Development of Measurement Concepts . . . . . 39

1. Integral Reactivity Measurements. . . . 440

2. Au tor ad iography . . . . . . . . . . 4 41

3. NDA Measurements. ............4 41

B. Development of Accounting Concepts. . . . . . 41

ACKNOWLEDGMENT. . . . . . . . . . . . . 4 42

REFERENCES. . . . . . . . . . . . . . 4 43 


\section{TABLES}

I

Probability That a Sample of Size $\mathrm{n}$ Will Include At Least One Out of $r$ Defects in a Population of 1000 .............. 19

II ${ }^{239} \mathrm{Pu}$ worth Data and Detection Sensitivities for ZPPR Assemblies. . . . . . . . . . . 
FIGURES

1

2

3

4

5

6

7

8

9

10

11

12

The decision-analysis process. . . . . . . 9

ZPPR matrix with a few drawers projecting

from the matrix tubes.............. 11

ZPPR drawer containing two rows of plutonium

plates interspersed with plates of depleted

uranium, sodium, and aluminum. . . . . . . . . 22

ZPPR storage canister. . . . . . . . . . 22

Reference core reactivity loss, ZPPR Assembly 1.25

Radial reactivity worth of ${ }^{239}$ tu in $\mathrm{ZPPR}$

assemblies ................ 27

Axial reactivity worth of ${ }^{239} \mathrm{Pu}$ in $\mathrm{zPPR}$

assemblies................. 27

Composite print of autoradiographs from fuel

drawers in the reactor............ 31

Autoradiographic image of ZPPR storage canister containing 24 4-in. plutonium fuel plates. . . 33

Autoradiographic image of partially filled

ZPPR storage canister with missing plate

(left side, third position from bottom). . . . 34

1 Autoradiographic image of partially filled

ZPPR storage canister with dummy solid

stainless steel plate in center of right row . . 35

Measurement setup for a ZPPR drawer showing

the HLNCC for neutron counting and the IAEA

intrinsic germanium detector with its

collimator for measurement of plutonium

gamma-ray line ratios............ 38 


\title{
PRELIMINARY CONCEPTS FOR \\ MATERIALS MEASUREMENT AND ACCOUNTING \\ IN CRITICAL FACILITIES
}

by

Donald D. Cobb and Joseph L. Sapir

\begin{abstract}
Preliminary concepts are presented for improved materials measurement and accounting in large critical facilities. These concepts will be developed as part of a study that will emphasize international safeguarding of critical facilities. The major safeguards problem is the timely verification of in-reactor inventory during periods of reactor operation. This will require a combination of measurement, statistical sampling, and data analysis techniques. Promising techniques include integral measurements of reactivity and other reactor parameters that are sensitive to the total fissile inventory, and nondestructive assay measurements of the fissile material in reactor fuel drawers and vault storage canisters coupled with statistical sampling plans tailored for the specific application. The effectiveness of proposed measurement and accounting strategies will be evaluated during the study.
\end{abstract}

\section{INTRODUCTION AND SUMMARY}

\section{A. Introduction}

Large, fast-critical assembly research facilities, used to simulate plutonium-fueled breeder reactors, currently are operating in many of the developed countries of the world. Two notable 
examples of such farilities are the Zero Power Plutonium Reactor ${ }^{1}$ (ZPPR) located at Idaho Falls, Idaho, and operated by Argonne National Laboratory (ANL) and the Fast Critical Assembly (FCA) located at Tokai, Japan. These very large facilities can simulate breeder reactors as large as 1000 MWe with cores containing as much as $3000 \mathrm{~kg}$ of fuel.

Both ZPPR and FCA are split table-type critical assemblies consisting of a large matrix of steel tubes divided into two halves. Thin plates containing fuel, structural, coolant, and blanket materials are placed in open metal "drawers" 2-in. square, which are inserted into the matrix tubes. The final configuration is formed by bringing the two halves of the reactor together and inserting fuel-bearing control rods to reach criticality. At ZPPR the inventory consists primarily of plutonium fuel plates, while FCA uses both plutonium and enriched uranium fuel.

Large critical facilities present a unique safeguards problem. Inventories can include tonnes of fissile material in relatively pure form divided among thousands of small fuel pieces. The wide-spread utilization of such facilities in nonweapons states represents a distinct proliferation hazard. Therefore, Safeguards and Security (SS) of the US Department of Energy (DOE) commissioned the Los Alamos Scientific Laboratory (LASL) and the Sandia Laboratories to develop advanced concepts for safeguarding critical facilities, with special emphasis to be placed on the international aspects of the safeguards problem. DOE./SS also administers the US Program for Technical Assistance to International Atomic Energy Agency (IAEA) Safeguards through its International Safeguards Project office (ISPO) located at Brookhaven National Laboratory. As part of this Program, IAASL and sandia have agreed to develop a safeguards approach for use by the IAEA in sareguarding critical facilities worldwide.

The study of advanced safeguards for critical facilities is part of on-going. generic studies of so-called integrated safeguards systems for a broad spectrum of nuclear facilities, in 
which Sandia and LASL, respectively, provide conceptual designs of advanced physical security and materials accounting systems.

This report is the initial milestone in the study of advanced concepts for materials measurement and accounting in critical facilities. A companion report ${ }^{2}$ prepared by Sandia Laboratories describes the physical layout of the ZPPR facility and gives concepts for improved physical security. Dur purposes in preparing this report are to identify promising concepts and techniques for improved materials measurement and accountability in critical facilities, and to outline a program plan and a technical approach for the follow-on study in which these concepts and techniques will be further developed. Specific recommendations for further investigations needed to develop both measurement and accounting concepts are presenteu in Sec. V. Appearance of a recommendation in this report does not imply that the development task will be performed during the study. Some concepts may be modified or abandoned as a result of further review and discussions with ANL personnel. In many cases the development effort is outside the scope of the planned study and will require additional funding and/or prioricy guidance from DOE/SS. At present it is anticipated that final results of the study will be available in the Spring of 1978 .

\section{B. Summary}

Complete physical inventories at critical facilities can only be performed infrequently, perhaps annually, because of the excessive burden placed on facility personnel and operations. Thus, a major problem in safeguarding criticai facilities is the timely verification of in-reactor inventories without serious disruption of reactor operations during the long periods between physical inventories.

We propose that periodic measurements of reactivity be combined with continuous sampling and measurement of fuel drawers for timely verification of the reactor inventory. When the reactor is initially loaded, a reference configuration would be established, and the reactivity and possibly other reactor 
parameters would be measured. These measurements are sensitive to the total inventory of fissile material in the reactor, but the sensitivity is dependent on the reactor size, composition, and material distribution. Periodically the reactor would be returned to the reference configuration for remeasurement and verification that the characteristics have not changed. Fuelbearing drawers would be sampled continually from the reactor inventory, as operating conditions permit, and verification measurements made in the reactor area using nondestructive assay (NDA) techniques. NDA "signatures" could be determined for each fuel drawer during its initial loading into the reactor matrix. Thus the verification of drawer contents would reduce to a relatively simple comparison of NDA signatures. A sampling plan for fuel drawers would be developed that is tailored to the distribution of special nuclear material (SNM) in the reactor matrix and the sensitivity of the integral measurements.

The storage vault would be maintained as an item control area. Vault-storage canisters would be stored under tamperproof seal. NDA measurement signatures would be established each time a canister is sealed. The NDA signature would be verified before a canister seal is removed.

Reactivity and other reactor parameters are already meásured at critical facilities. The sensitivity of these integral measurements to the reactor inventory must be characterized for each reference critical assembly. Also, portable instrumentation that could be used by inspectors for independent verification based on integral measurements should be considered.

Specific NDA techniques to be investigated for measurements of fuel drawers and vault canisters are gross neutron and neutron coincidence counting, gamma-ray spectroscopy, and autoradiography in which images of individual fuel plates are'produced on $x$-ray film. The autoradiography technique has already been developed and successfully applied at ANL to drawers and canisters containing plutonium fuel plates. Neutron and gamma-ray instruments developed at IASL have already been fielded by IAEA inspectors at the Japanese FCA facility; however, some further developmental 
effort is reguired to characterize and adapt this instrumentalion for this specific application.

The proposed verification techniques are sensitive to different properties and characteristics of the fissile material. Although it may be possible to subvert any one technique, a combination of these techniques and related sampling plans provides increased effectiveness and reduced vulnerability. The detection sensitivity for a combination of techniques can be a very complicated function. The question of which measurement and accounting strategies afford the best assurance depends on a variety of factors including operational constraints. Computerized modeling and simulation methodology and powerful decision analysis tools developed at LASL during previous safeguards systems studies ${ }^{3-5}$ will be used to address these complexities during the study. The ZPPR facility has been selected as a reference to maintain the necessary contact with reality. The effectiveness of various measurement and accounting strategies against diversion will be evaluated and compared using the modeling and simulation approach. Our experience indicates that this approach yields reliabie results and provides a credible basis for recommendations.

II. MATERIALS MEASUREMENT AND ACCOUNTING SYSYEM

\section{A. General Description}

The materials measurement and accounting system (MMAS) performs three general functions with regard to SNM accounting in any nuclear facility:

- data collection (including measurements and maintenance of the data base),

- data analysis (e.g., for detection of diversion), and

- data dissemination and reporting.

Current safeguards procedures for inventory control rely on material balance accounting following infrequent shutdown and physical inventory. 6-8 The classical material balance is 
drawn around the entire facility or major portions thereof, and is formed by adding all measured receipts to the initial measured inventory, subtracting all measured shipments, and subtracting the ending measured inventory. Warning and action limics are usually established at the $2-\alpha$ and $3-\alpha$ levels, respectively, where $\alpha$ is the uncertainty ione standard deviation in the material balance due to exrors in measurement.

Conventional accounting procedures are implemented by dividing the facility into material control areas (MCA). There are two types of MCAs, item control areas (ICA) and material balance areas (MBA). In ICAs, identifiable items are maintaiñed under seal, for example, in a storage vault. Items are usually not remeasured unless the seal is removed, except that verification measurements may be made at the time of physical inventory. MBAs generally encompass areas where bulk materials are used, and the identification and maintenance of sealed iteas is not practical. Physical inventories and measured material balances are mainstays of accounting in MBAs.

All transfers of significant quantities of SNM between MCAs should be measured both by the shipper and the receiver. Significant discrepancies between shipper and receiver values should be investigated. A so-called book inventory is maintained for each MCA. The initial contents of this book inventory are the values from the last physical inventory. The quantities, forms, and locations of SNM in the book inventory are updated to reflect each transfer of material. A physical inventory is performed at the end of each accounting period to verify the ending book inventory, and unexplained differences between the ending book and physical inventories are investigated.

A related operational requirement on the MMAS is the maintenance of an effective reasurement control program. This involves (1) the establishment of plans and procedures for safeguards measurements; (2) the maintenance of physical standards, instrument calibrations, and records of instrument performance; and (3) the maintenance and upgrading of safeguards instrumentation. The measurement control program must keep up-to-date records of 
precision and accuracy for each instrument because the significance of shipper/receiver and inventory differences is determined to a large extent by the quality of the measurements.

\section{B. Improved Materials Accounting}

Although conventional material balance accounting is essential for effective safeguarding of nuclear material, it has inherent limitations in sensitivity and timeliness. Sensitivity is limited by uricertainties in measurements that can mask losses of SNM, especially in facilities with high throughput and/or large inventories. Timeliness is limited by the frequency at winch the physical inventory is taken. There are practical limits on how often a facility can shut down for inventories and still be productive. During periods of routine operation, materials control is vested largely in the physical security system, in administrative procedures for handling materials, and in secure storage of sealed items.

Materials control can be made more effective if conventionai. accounting methods are augmented by recently developed nondestructive assay technology and poweriul statistical dataanalysis techniques combined with supportive computer and database-management technology. ${ }^{9-12}$ Recent studies $^{3-5}$ have demonstrated that significant improvements, both in timeliness and sensitivity, are achieved by dividing a facility into smaller accounting envelopes referred to as unit-process accounting areas. Techniques for rapid measurements, especially NDA, are used to verify material transfers between unit processes in near-real time. Inventories in the unit processes are verified frequently even though the inventory measurements may be rather crude relative to corventional physical inventory measurements. In other worcs, rapid and unobtrusive measurements are made during facility operations to provide timely verification of transfers between unit processes and frequent checks on the "book inventory" in each unit process. The material balances formed from the timely inventory and transfer measurements are called dynamic material balances to distinguish them from 
balances drawn after a shutdown and physical inventory. Our experience incicates that these concepts are effective and flexible in applications to a variety of facilities including both research and production types.

\section{Diversion Detection}

Analysis of materials accounting data for possible diversion of SNM constitutes one of the major functions of the MMAS. Diversion may occur in two basic patterns: short-term diversion, which refers to the single thet:t of a relatively large amount of SNM, and long-term diversion consisting of repeated thefts of SNM on a scale tco small to be detected in a single material balance because of measurement uncertainties.

The use of unit process accounting and dynamic material balances enhances the ability to detect such diversions, but the operator of the safeguards system may be inundated with materials accounting data. Furthermore, although these data contain much potentially useful safeguards information, the significance of any isolated (set of) measurements may change from day to day depending on operating conditions. Thus, the safeguards system operator is presented with a complex body of information from which he must repeatedly determine the safeguards status of the facility. It is imperative that he be assisted by a coherent, logical framework of tools that address these problems.

Decision analysis, 13 which combines techniques from estimation theory, decision theory, and systems analysis, is such a framework, and is well suited for statistical treatment of the imperfect dynamic material balance and inventory data that become available sequentially in time. Its primary goals are (1) detection of the event(s) that SNM has been diverted, estimation of the amount(s) diverted, and (3) determination of the significance of the estimates. Figure 1 illustrates the decision-analysis process.

The detection furytion is based on acceptance of the hypothesis $\mathrm{H}_{1}$ that some (initially unknown) amount of SNM has been diverted, versus the hypothesis $H_{0}$ that no diversion has 


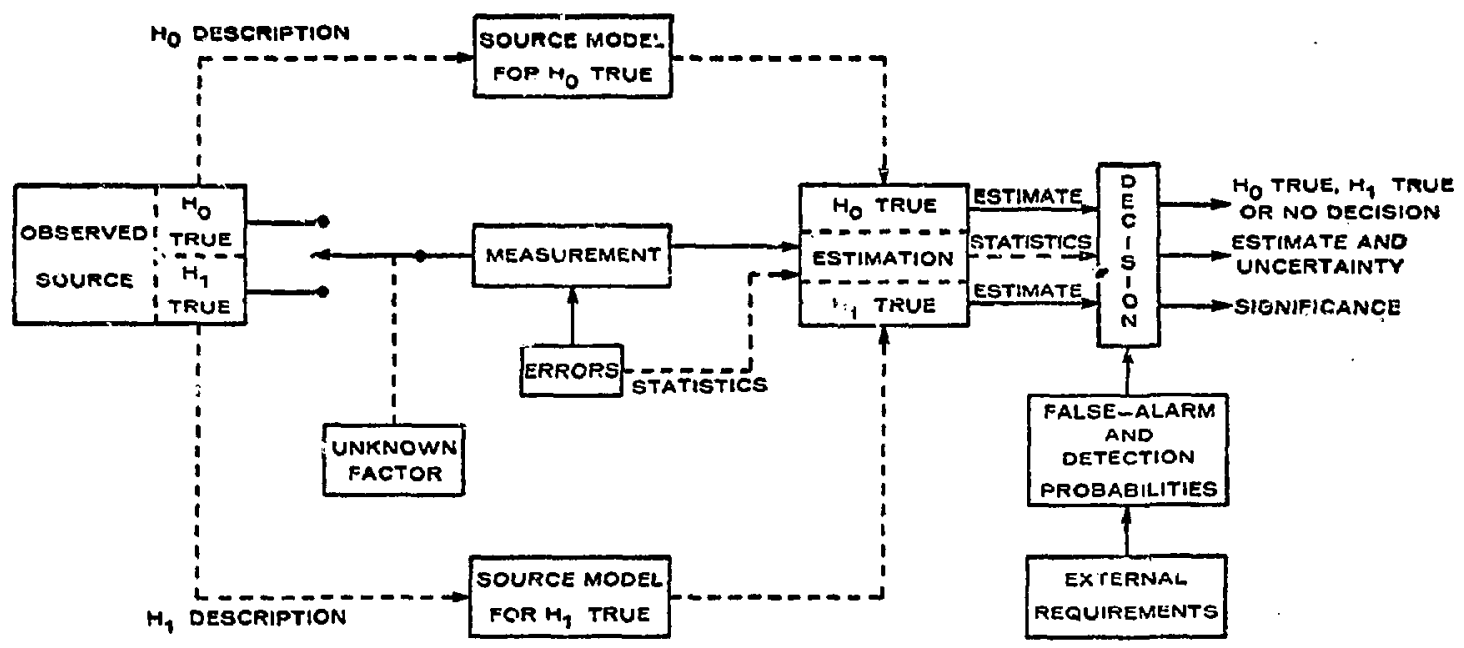

Fig. 1. The decision-analysis process.

occurred. The detection threshold is determined by the desired false-alarm and detection probabilities.

The estimation function can take several forms, including that of the Kalman filter applied to the material balance equation. 14 Additional information such as detailed process models may be incorpoiated as desired. Effective estimation algorithms can greatly improve the detection sensitivity.

Pattern-recognition techniques can be very useful for determining the significance of the estimates. One such tool is the alarm-sequence chari, 15 which indicates (I) those materialbalance sequences for which the possibility of diversion has been detected, (2) the false-alarm probability (significance) for that level of diversion, and (3) the length of the sequence.

Decision analysis based on mathematically derived decision functions is appealing because it can quantify intuitive feelings and condense large collections of data into a smaller set of more easily understood descriptors, or statistics. It can also eliminate personal biases and other errors caused by subjective evaluation of data, while providing a degree of consistency for the decision process. 
The usefulness of the tests is related directly to how well they are human engineered. The safeguards system operator must be able to apply them quickly and easily in whatever fashion seems most appropriate at the moment, within the limit of good statistical-analysis practice, and with reasonable assurance that he can understand the neaning of the results.

III. MATERIALS ACCOUNTING IN CRITICAL FACILITIES*

\section{A. General Considerations}

The purpose of a critical facility such as ZPPR is to study the characteristics of plutonium-fueled, fast-breeder power reactors. ${ }^{1}$ Cores involved in these studies may contain as much as $3000 \mathrm{~kg}$ of plutonium. Most of the plutonium fuel at ZPPR is a ternary alloy of plutonium, depleted uranium, and molybdenum containing about 28 wto plutonium. Fuel plates manufactured from this alloy are nominally $0.25-i n$, thick, 2-in. high, and 1to 8-in. Iong, including a stainless steel jacket. The inventory includes many thousands of these plates. The fuel plates are placed in reactor drawers along with coolant, blanket, and other materials (Sec. IV). The reactor drawers are loaded into the reactor matrix, which is divided into two arrays of stainless steel tubes (Fig. 2). When not in use the fuel plates are placed in canisters for vault storage (Sec. IV).

During operation the reactor matrix may be loaded with several thousand drawers. Fuel plates are placed in roughly half of these drawers, which may contain a large fraction of the total plutonium inventory at the facility. The reactor is initially loaded in a reference configuration. A relatively small number of drawers are changed during periods of operation that may extend for several weeks. These drawer changes produce small perturbations on the total inventory of plutonium in the

Much of the material in this chapter is based on information supplied by personnel at the ZPPR facility. 
reactor. Major reloadings of the reactor occur infrequently, perhaps once or twice a year.

The operation of a critical facility is in response to national priorities and the demands of research and development. Because these factors change in time, standard operating procedures or normal operations are difficult to define, in contrast with production plants where the goal is almost always to operate the process near steady state for reasons of economics and product quality. Nonstandard operation makes the job of monitoring SNM more difficult.

Two positive safeguards aspects at critical facilities are that (I) the SNM is very well characterized, and (2) the total facility inventory may not change significantly over long periods. The major alteration in the plutonium fuel is the radioactive decay of the plutonium isotopes, especially the decay of ${ }^{241_{\mathrm{Pu}}}$ to ${ }^{241_{\mathrm{Am}}}$. In addition, only a small number of physical forms of relatively pure SNM are

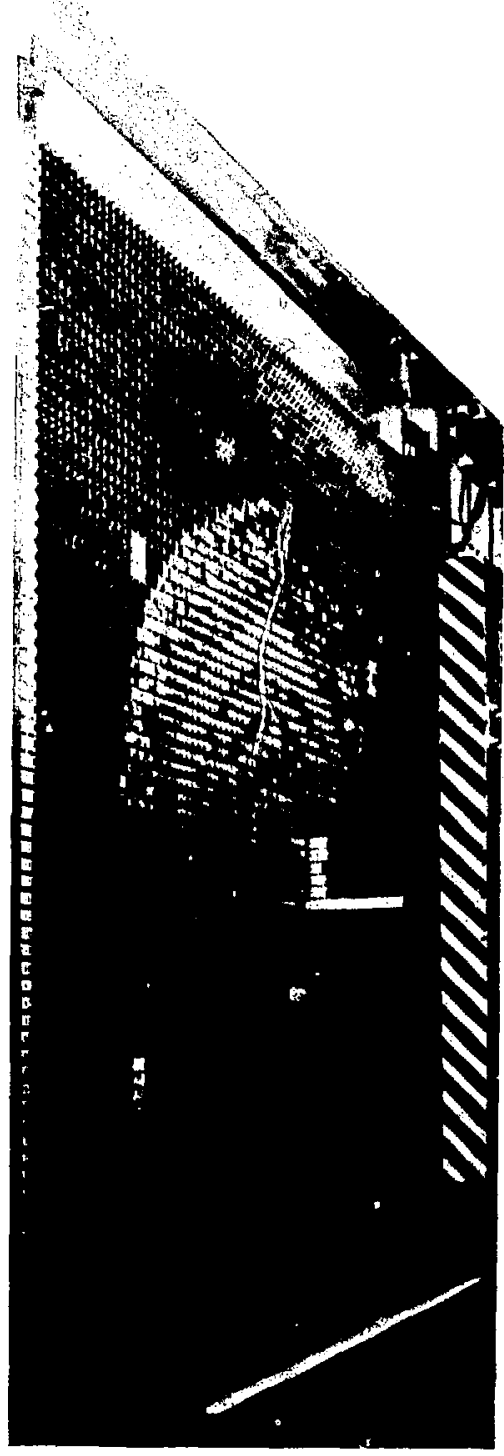

Fig. 2. ZPPR matrix with a few drawers projecting from the matrix tubes. 
present in the inventory, and these are not lisely to change over the life of the facility. For these reasons the application of NDA methods and the development of appropriate physical standards should be relatively straightforward.

As is typical of other relatively small research facilities, the staff at a critical facility is composed of a few tens of highly trained scientists usually operating on a tight budget. Proposed changes in materials accounting requirements or procedures, even changes that appear to be small, may have a significant impact on operations. Obviously, the value of each proposed safeguards improvement must be carefully balanced against the impact on operation of the critical facility. On the other hand, current inventory methods based on piece counting or item identification are laborious and time consuming. Alternative techniques that reduce the burden of the inventory process would be of positive benefit to the facility.

\section{B. Material Transfers}

Operating critical facilities such as ZPPR are not likely to receive or ship substantial quantities of SNM. External transfers normally will be infrequent, and usually will involve only a small number of fuel plates. All shipments and receipts should be verified by direct NDA measurement.

Within the critical facility, the vault and the reactor are maintained as separate material control areas, and there are transfers of fuel plates between these areas that should be verified by direct measurement. Large numbers of transfers are required during a major reloading of the core. During operation of the reactor, relatively few drawer changes are made.

The vault should be maintained as an item control area. Vault-storage canisters should be placed under tamper-proof seal. The contents of canisters should be verified by NDA measurement. This requires that NDA instrumentation be available for measurement of vault canisters (Sec. IV). If the vault is used for temporary storage of SNM in unsealed containers, e.g., 
in drawers, the temporary storage area in the vault should be sealed. If it is necessary to store fuel drawers in the vault temporarily, the contents of the drawers should be measured both entering and leaving the vault area. Administrative controls would limit the length of time that fuel drawers could be stored in the vault.

It may be necessary to measure the contents of fuel drawers sent to the reactor area using NDA instrumentation. Ideally, drawer measurements would be made in the reactor area prior to loading the drawer inco the matrix. Fuel drawers removed from the reactor matrix would be measured before leaving the reactor area. NDA techniques for making drawer measurements in the reactor area should be pursued (Sec. IV).

In summary, internal transfers typically consist of loading reactor fuel drawers with fuel plates from vault-storage canisters, or unloading plates from fuel drawers into canisters. These transfers, and other variations such as drawer-to-drawer or canister-to-canister, could be verified by appropriate combinations of the drawer and canister NDA measurements. Data from the NDA instrumentation would be entered directly into the computerized data base. The safeguards information system would use these data to verify transfers, flag discrepancies, and update the book inventory.

\section{Inventory Verification}

The book inventory consists of the contents of fuel drawers and vault canisters. A cauister is identified by a unique serial number and by its location in the vault-storage bins. A fuel drawer is identified by its location in the reactor matrix (or by its position in the vault, if temporary storage is permitted). The location of each fuel piece is recorded so that inventory records are available in terms of fuel manufacturer, isotopic content, plate length, etc. The original fuel-assay data from each manufacturer are available, and these data are updated periodically to reflect changes in isotopics due to 
radioactive decay. At 2 PPR unique identifiers on the fuel pieces are also used for identification.

1. Physical Inventory. Because of the burden on the facility, complete physical inventories can only be performed infrequently. In the past, physical inventories have generalj.y relied on piece counting or item identification with visual inspection of the fuel plates. Only a small fraction of the inventory would be verified by NDA. This procedure is not only laborious and time consuming, but also results in significant personnel radiation exposure. More recently, autoradiography measurements have been used to verify inventories (Sec. IV).

For purposes of discussion, consider the following scenario for a physical inventory. All of the fuel is first removed from the reactor and stored in the vault. Under this scenario, it would be advantageous to schedule physical inventories to coincide with major reloadings of the reactor, which typically occur once or twice a year. Each canister, after it has been filled with fuel plates and sealed, is measured by NDA before returning it to the vault. The remainder of the vault inventory would be remeasured only if the canister had not been measured since the previous physical inventory.

As an example, if we assume that 500 canisters are required to hold all the fuel plates from the reactor, and that each canister measurement requires an average of $5 \mathrm{~min}$, then approximately $40 \mathrm{~h}$ would be required to make the inventory measurements. If this burden is intolerable, NDA measurements might be made on a statistically significant sample of the vault canisters, while a partial verification is obtained for the remaining canisters using a lëss burdensome technique like autoradiography.

The problem remains: What is to be done when the reactor is reloaded after the physical inventory? Fuel drawers loaded into the reactor, perhaps 1500 or so in the case of ZPPR, would be measured in the reactor area. Because this is the initial inventory in the reactor for the next accounting period, it is desirable to have 100 z verification. Here again, rapid NDA techniques 
are required. Reactivity and other parameters of the new reference configuration would also be measured.

of course physical inventories could be performed for the reactor and vault areas at any time. If NDA measurements can be made in the reactor area, the reactor inventory could be verified essentially in place. However, then the problem becomes: what is to be done when there is a major reloading of the reactor? Drawer and canister measurements required to verify transfers during a major reloading could amount to a large fraction of the effort required for a physical ir.rentory. For this reason, we favor scheduling the physical inventory to coincide with a major reloading of the reactor. If this is not possible, the reactor inventory should be verified in place.

It is clear that whatever approach is used, the physical inventory is, and will continue to be, a difficult problem at critical facilities. If effective techniques can be developed for rapid and continuous verification of the reactor inventory, the physical inventory burden could be reduced.

2. Timely Verification of Reactor Inventory. We believe that the main problem in safeguarding critical facilities, both from the domestic and international viewpoints, is the timely verification of reactor inventories without severe disruption of reactor operation. Therefore, much of the effort of our study will be directed towards the development and evaluation of techniques for rapid verification, or checking, of the reactor inventory during periods of reactor operation. To be practical, such techniques must be effective and yet unobtrusive. Some promising measurement techniques already identified for further study are discussed in sec. IV, and include reactivity, antoradiography, and other NDA measurement methods.

It is likely that a strategy combining several measurement and accounting techniques will be required to provide the desired levels of assurance and timeliness. The techniques are sensitive to different properties and characteristics of SNM. Although it may be possible to subvert any one technique, it would be very difficult to subvert several of them used in combination. It is 
also true that the measurement methods will have to be combined with statistical sampling plans and data analysis tools tailored for this specific application. For example, reactivity measurements are most sensitive to fuel near the center of the core (Sec. IV). If the reactor inventory is to be verified using measurements of reactivity in combination with NDA measurements made on a sampling of lue? drawers, it makes good sense to sample more drawers near the edge of the core.

The probability of detection of missing material may be straightforward to calculate or to determine experimentally for any single measurement technique. However, the detectionprobability function can be very complicated for a combination of techniques. Also the question of which measurement strategy is best depends on a variety of factors that include the detection sensitivity and operational constraints. Computerized modeling and simulation methodology developed at LASL during previous safeguards systems studies has proven to be effective in answering such questions. 16 In the follow-on study, we will use this methodology to compare various strategies for rapid verification of reactor inventory. The strategies will include combinations of measurement methods, the frequency of such measurements, the application of sampling plans and data anaiysis tools, and the effect of operational constraints. Our approach will be to first model the transfers and inventory of SNM in an operating critical facility using ZPPR as a reference. Models of the accounting measurements will be applied to the transfers and inventory of SNM, and the data resulting from various strategies will be evaluated and compared.

To concepts related to rapid inventory verjicication are especially important, and will be developed in the modeling and simulation studies. First, fuel drawers in the reactor matrix will be sampled continuously, as operations permit, for measurement in the reactor area. The continuous sampling plan would be tailored to the distribution of SNM in the reactor and the frequency and sensitivity of reactivity measurements. Examples of 
sampling plans are given in the next section for the purpose of illustration.

The second concept is that differences between similar measurements are very sensitive to losses of SNM, and these should be exploited whenever possible. If the same instrument is used to make measurements on material that is essentially unchanged, the uncertainty in a difference between such measurements is the error component due to random fluctuations of the instrument. This error component can be made quite small; in the case of NDA measurements it is usually just the error associated with counting statistics. Thus, verification of SNM content can reduce to a go-no-go comparison of measurement signatures.

This concept can be applied to measurements of fuel drawers, vault canisters, and reactor parameters. For example, during a major reloading of the core, all the fuel drawers and the reactivity of the new reference configuration would be measured. During operation of the reactor, measurement signatures would be verified for zuel drawers that are selected as part of the sampling plan. Periodically, the reactor would be returned to the reference configuration for verification of the reactivity.

3. Sampling Plans. Sampling plans have been used for quality control by industry for many years. 17 For example, consider a product lot consisting of 'J items manufactured by some process. Assume that $r$ of these $N$ items do not meet product specifications. These $r$ items are said to be defective. The lot will be shipped to the purchaser if it can be demonstrated with a high degree of certainty that $r / N<f$, where $f$ is a small fraction. Under the hypothesis that $r=f N$, i.e., that the lot is a reject, the question is: What size sample $n$ of the $\mathbf{N}$ items must be selected at random in order that the sample will include at least one of the $r$ defects, with a certain probability? We refer to this probability as the probability of detection, DP. The answer to this question is given by an elementary result from probability theory: 


$$
D P(n, r, N)=1-c_{n}^{N-r} / C_{n}^{N}
$$

where

$$
c_{x}^{y}=y ! /[x !(y-x) !]
$$

is the combination of $y$ items taken $x$ at a time. For example, if $\mathrm{N}=100, \mathrm{r}=5$ ( $\mathrm{f}:=58$ ) and the desired detection probability is $95 \%$, one can show ulsing Eq. (1) that $n$ must be 44 .

In order to apply Eq. (1), two additional conditions must be satisfied. First, the method used to determine if an item is defective must have an associated measurement error that is insignificant compared with the size of the defect. If this condition is satisfied, the sampling is said to be "by attributes." If it is not satisfied, the measurement error must be included in the analysis, and the sampling is said to be "by variables."17 We will not discuss variables sampling further.

The second condition is that, as items are selected for the sample, they are not returned to the total population of items. This is referred to as sampling without replacement. If each item selected for the sample is measured and then returned to the population before the next item is selected, this is referred to as sampling with replacement, and Eq. (1) must be modified as follows :

$$
\operatorname{DP}(n, r, N)=1-(1-r / N)^{n}
$$

For our example with $N=100, r=5$, and $D P=958$, Eq. indicates that $n$ must be about 58. Clearly a larger sample is required when using sampling with replacement because the identity of each item sampled from the population is lost after measurement.

Sampling plans are used extensively in nuclear materials control, especially for the verification of inventories consisting of discrete items. ${ }^{18}$ The following simplified example is illustrative of the possible application of sampling plans to 
the verification of reactor inventories at critical facilities. We assume that the reactor matrix contains 1000 fuel drawers, and that each fuel drawer should contain exactly $\mathrm{l} \mathrm{kg}$ of plutonium in the form of metal plates. A fuel drawer will either contain the proper $1-k g$ quantity of plutonium, or the entire amount will be missing. Note that attributes sampling could be used to detect the removal of only part of the material in a drawer. The amount of material that is detectable on a go-no-go lattribute) basis depends on the sensitivity of the measurements. For this simplified example, we assume that the entire drawer content is removed, and that an attributes sampling pian can be used to detect defective drawers, i.e., those from which plutonium has been diverted.

In Table I the probability of detection DP for sampling both with and without replacement is given as a function of the

\section{TABLE I}

PROBABILITY THAT A SAMPLE OF SIZE $n$ WILL INCLUDE AT LEAST ONE OUT OF $r$ DEFECTS IN A POPULATION OF 1000

\begin{tabular}{|c|c|c|c|c|c|c|c|c|}
\hline \multirow{3}{*}{$\begin{array}{l}\text { Sample } \\
\text { Size, n }\end{array}$} & \multicolumn{8}{|c|}{ Number of Defects, $r$} \\
\hline & \multicolumn{4}{|c|}{ Without Replacement } & \multicolumn{4}{|c|}{ With Replacement } \\
\hline & $I$ & 2 & 5 & 10 & 1 & 2 & 5 & 10 \\
\hline 50 & 0.05 & 0.10 & 0.23 & 0.40 & 0.05 & 0.095 & 0.22 & 0.39 \\
\hline 100 & 0.10 & 0.19 & 0.42 & 0.68 & 0.095 & 0.18 & 0.39 & 0.63 \\
\hline 150 & 0.15 & 0.28 & 0.56 & 0.80 & 0.14 & 0.26 & 0.53 & 0.78 \\
\hline 200 & 0.20 & 0.36 & 0.68 & 0.91 & 0.18 & 0.33 & 0.63 & $0.9,7$ \\
\hline 300 & 0.30 & 0.51 & 0.84 & 0.98 & 0.26 & 0.45 & 0.78 & 0.95 \\
\hline 400 & 0.40 & 0.64 & 0.93 & 1.00 & 0.33 & 0.55 & 0.865 & 0.98 \\
\hline 500 & 0.50 & 0.75 & 0.97 & 1.00 & 0.39 & 0.63 & 0.92 & 0.99 \\
\hline 600 & 0.60 & 0.84 & 0.99 & 1.00 & 0.45 & 0.70 & 0.95 & 1.00 \\
\hline 800 & 0.80 & 0.96 & 1.00 & 1.00 & 0.55 & 0.80 & 0.98 & 1.00 \\
\hline 1000 & $1.00^{\mathrm{a}}$ & 1.00 & 1.00 & 1.00 & 0.63 & 0.86 & 0.99 & 1.00 \\
\hline
\end{tabular}

a probabilities $>0.995$ have been rounded to 1.00 . 
sample size $\mathbf{n}$ and the number of defective drawers $r$. Note that DP is the probability that the sample will include at least one of the defective drawers. If, for example, the goal is to detect the presence of 10 cefective drawers in the reactor matrix 110 $\mathrm{kg}$ of missing plutonium in this example) with a detection probability of $55 \%$, the sample size required is about 260 if the sampling is performed without replacement, and about 300 if replacement sampling is used. Tlie results in Table I can be applied to any total population $N$ because the ratio $n / N$ is constant for fixed values of $r$ and $D P$.

Although this simplified example is instructive, several complications would be encountered in practical application. The number of defective drawers in the matrix could increase in time depending on the diversion strategy. Normal drawer changes would perturb the population. As discussed previously, the sampling plan would likely be designed in combination with periodic reactivity measurements. In many cores the fuel drawers would contain different quantities of SNM, and the sampling plar, should be weighted to reflect whe distribution of material in the fuel drawers. If one wants to detect the removal of individual fuel plates from the drawers, the errors in measurement could become significant relative to the amount of missing material, so that a variables sampling plan would be required. The effect of such complexities taken in combination can best be evaluated using computerized modeling and simulation techniques.

From the operational viewpoint, fuel drawers cannot be continuously sampled from the reactor matrix for verification measurements. Sampling might be scheduled during the evening, or on weekends, or during other periods when the reactor is not operating. A reasonable goal might be to sample and measure about 50 drawers per week. Sampling without replacement is always the method of choice if lise entire sample is drawn at one time. Frequent sampling for continuous inventory verification may require sampling with replacement. If only part of the total sample is drawn each week, this partial sample should be returned to the total population before the next partial sample 
is taken. This leads to a combined sampling plan in which only the items in each partial sample are selected $w$ th thout replacement from the total population. In this case, if $n$ is the total sample size desired and $m$ is the size of each partial sample, the detection probability is given by

$$
\operatorname{DP}(n, m, r, N)=1-\left(C_{m}^{N-r} / C_{m}^{N}\right)^{n / m}
$$

where $n / m$ is the number of partial samples of size $m$ required to make up a total sample of size $n$. Values of DP obtained using Eq. (3) differ by less than 18 from the corresponding values obtained by sampling with replacement [see Eq. (2)] for the parameter ranges given in Table $I$. Therefore, a combined plan should be essentially equivalent to sampling with replacement.

IV. MATERIALS MEASUREMENTS IN CRITICAL FACILITIES

Critical assembly mockups of fast breeder reactors such as ZPPR and FCA require very large inventories of plutonium and enriched uranium fuel. The fuel is usually in the form of thin plates (1/16- to 1/4-in. thick, 2-in. wide and 1 - to 8 -in. 1ong) and small rods $(3 / 8-i n$. diam by $3-$ to $6-i n$. long). The fuel plates are placed in drawers, 2-in. square and up to $36-i n$. long, and interspersed with appropriate nonfissile mockups of structural, coolant, and blanket materials. A typical drawer includes an 18-in. active length containing either one or two rows of fuel plates ( 0.5 or $1.0 \mathrm{~kg}$ of fissile plutonium) and an axial blanket region consisting primarily of depleted uranium and sodium. A ZPPR drawer containing two rows of plutonium plates inteispersed with sodium, depleted uranium, and alumi.um is shown in Fig. 3. The drawers are stacked into two halves of the reactor, which are brought together remotely to perform the experiment.

When outside the reactor the fuel plates and pins are stored in specially designed canisters such as that shown in Fig. 4. 


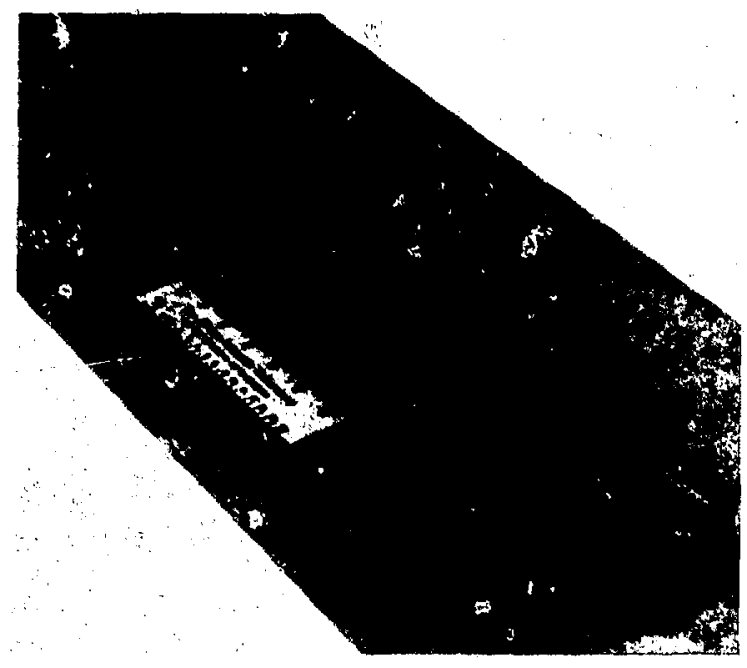

Fig. 3. ZPPR drawer containing two rows of plutonium plates interspersed with plates of depleted uranium, sodium, and aluminum.

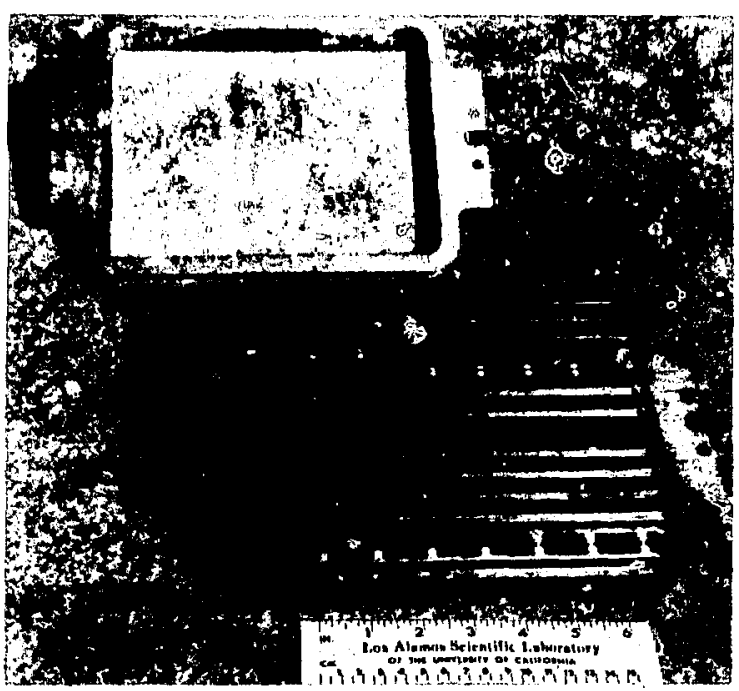

Fig. 4. ZPPR storage canister.

At ZPPR, administrative controls prohibit mixing plates and pins within the same canister, and, except for rejects, only plates or pins of the same length may be stored in a single canister. A canister may not contain more than $2.7 \mathrm{~kg}$ of fissile material.

Because of the large number of fuel plates involved and their disposition inside the drawers, verification of the plutonium content of each plate individually is time consuming and may adversely affect the operation and productivity of the experimental program. A complete physical inventory at ZPPR, including visual inspection of every item and NDA measurements on 58 of the items, required 12 men on 2 shifts for 3 wk. Because of the accumulated radiation dose, an individual's exposure was limited to 1 wk, thereby requiring the use of 36 persons to perform the inventory.

It would therefore be very desirable to inventory fuel material "collectively" in relatively large units, especially 
during the long periods between infrequent, but complete, physical inventories. Examples of such collective measurements would be to verify the contents of an entire drawer or canister without removing individual plates or to verify the contents of the entire ZPPR reactor without removing individual drawers. Several promising techniques for these collective verifications are discussed below. Thus far we have concentracea on verification of plutonium plates, which constitute the most important part of the ZPPR inventory.

\section{A. Integral Reactivity Measurements}

The ability of a reactor or critical assembly to sustain a chain reaction is characterized by the reproduction factor, $k$, defined as the ratio of the number of neutrons in any one generation to the number of corresponding neutrons in the immediately preceding generation. The value of $k$ determines the behavior of the neutron population within the assembly. If $k$ is exactly equal to unity, a chain reaction will be exactly maintained and the neutron population will remain constant with time. Such a system is said to be critical. If $k<1.0$, the system is said to be subcritical, and any neutron introduced into the system will produce chains that eventually die out. If $k>1.0$, the assembly is said to be supercritical, and, after transients die out, the neutron population will rise exponentially. The time for the neutron population to increase by a factor of $e$ in a supercritical assembly is called the stable reactor period. The stable period is uniquely related to the reproduction factor, $k$, through the reactivity, $\rho$, of the system, which is defined as $(k-1) / k$. The unit of reactivity often used at ANL is the "inhour" (Ih); this is the amount of positive reactivity required to produce a stable period of $1 \mathrm{~h}$. For those more familiar with the $\$$ unit of reactivity, $1 \$$ w $1020 \mathrm{Ih}$ in ZPPR plutonium assemblies.

An integral reactivity measurement is the establishment of a supercritical configuration and the measurement of the resulting reactor period. The reactivity and corresponding period of a 
system containing fissionable material depends upon the neutron balance or relative extent to which neutrons take part in three main processes: (1) loss or escape from the system, (leakage); (2) nonfission absorption in either fuel or nonfissile material such as structure, coolant, or moderator, (capture); and (3) fission absorption in fuel, (fission). The rates at which these competing processes occur are governed by the size, shape, and composition of the assembly. If no changes have occurred in a given configuratior (size, shape, composition, temperature, etc.), it will always have the same reactivity and always produce the same reactor period within the measurement uncertainties. If fuel material is removed from the assembly without additional compensating changes, the reactivity will decrease and such removal will be observed as an increase in the reactor period. In the proposed safeguards system a reference configuration would be checked periodically to verify that reactivity has not changed.

The effectiveness of integral reactivity measurements as a diversion-detection technique will depend upon the sensitivity with which these measurements can detect missing material. specifically, how much plutonium can be removed before reactivity measurements will detect such removal? The factors influencing the diversion sensitivity are the reproducibility of the reference reactivity measurements and the reactivity worth of fuel in the reference assembly.

In fast critical assemblies such as $2 P P R$, differences in reference reactivity measurements may arise from temperature variations, irreproducibility of table closure and control rod positions, inaccuracies in the reactivity measurements and unavoidable changes in the core composition, particularly the decay of fissionable ${ }^{241} \mathrm{Pu}$. The temperature of the ZPPR cell can be held constant to within $\pm 0.25^{\circ} \mathrm{F}$. Therefore, if the approach to critical is always the same, uncertainties associated with temperature variations during reference measurements should be relatively small. Experience at ZPPR indicates that overall reproducibility of reactivity measurements on the same 
assembly over a 1- or 2-day period should be better than

1 Ih. However, over a longer time period the decay of the fissionable isotope ${ }^{24}{ }^{\mathrm{Pu}}$ (13-yr half-life), present in small quantities in the ZPPR fuel alloy, produces consistent and observable reactivity loss with time. Figure 5 (Ref. 19) shows the results of reactivity measurements made on ZPPR Assembly 1 over the course of several weeks. The measured reactivity decreased by about 5 Ih. Even though the calculated

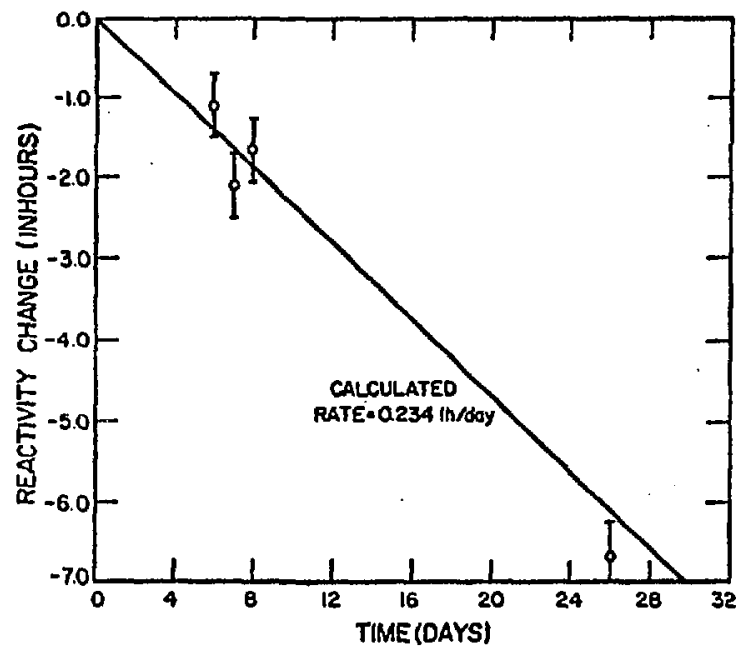

Fig. 5. Reference core reactivity loss, ZPPR Assembly 1 . rate of $-0.234 \mathrm{Ih} /$ day agreed well with the measured decrease, the effect of ${ }^{241} \mathrm{Pu}$ decay may produce significant uncertainties in long-term, reference criticality checks. In conjunction with a safeguards program, it will therefore be necesessary to accumulate experimental data on reference configurations to determine an accurate experimental value of reactivity loss due to ${ }^{241}$ Pu decay.

Based on a review of ZPPR experience and discussions with personnel at ANL-East and -West, it appears that in a program designed to use integral reactivity checks for inventory verification, a discrepancy of 3 Ih between the expected and observed reference reactivity can be used to "trigger a safeguards alarm" (i.e., require further investigation and explanation) without producing an excessive number of false alarms.

The amount of fuel that can be removed within the 3-Ih limit depends upon the reactivity worth of the ZPPR fuel plates in the reference core. Although the worth of actual plates has not been measured, extensive mappings of the worths of small ${ }^{239} \mathrm{Pu}$ (18 ${ }^{240} \mathrm{Pu}$ ) samples have been performed. We have reviewed such 
measurements performed from 1971 to 1977 in ZPPR assemblies 2 through 7 as reported in ANL progress reports (ZPR-TM series). These assemblies generally had a core volume of 2400 to $2550 \mathrm{~L}$ and contained $21050 \mathrm{~kg}$ of plutonium in 21550 core drawers. Notable exceptions were Assembly 3-1A, which contained a $3350 \mathrm{~L}$ core, and Assembly 7, which incorporated blanket material within the core region and contained $1360 \mathrm{~kg}$ of plutonium.

The reactivity worth of ${ }^{239} \mathrm{Pu}$ strongly depends on its location within the core. Typical radial traverses taken near. the core midplane are shown in Fig. 6 for several of the ZPPR assemblies. The data plotted in the figure include the extreme values. Additional points not plotted fall within the indicated band. In general, for a homogeneous, uniformly loaded, fast reactor core, the ${ }^{239} \mathrm{Pu}$ worth will peak at the center and monotonically decrease with increasing radius. In some of the ZPPR configurations, perturbations due to control rods, sooium experiments or loading variations caused the worth to dip in the central region. However, in all cases the minimum worth occurred at the outer edge of the core.

Axial worth traverses of ${ }^{239} \mathrm{Pu}$ taken at or near the reactor centerline are shown in Fig. 7. Except for a configuration in Assembly 5 that simulated fuel slumping during a reactor disassembly accident, the axial worth profiles exhibit the "classical" shape with the minimum core worth occurring at the core edge ( $\mathrm{L}=18$ in.).

From Figs. 6 and 7 it is apparent that the minimum plutonium worth will occur at the outermost corner of the core (in the outer drawers at the core-axial blanket interface). Although measurements have not been made in this region, the worths there can be estimated by assuming separability of the radial and axial profiles. The data necessary to deduce the minimum plutonium worths are listed in Table II for several ZPPR assemblies. The approximate outer radial boundary of the core is listed in column 2 of Table II and the corresponding ${ }^{239} \mathrm{Pu}$ midplane worth at the boundary, as obtained from Fig. 6 , is listed 


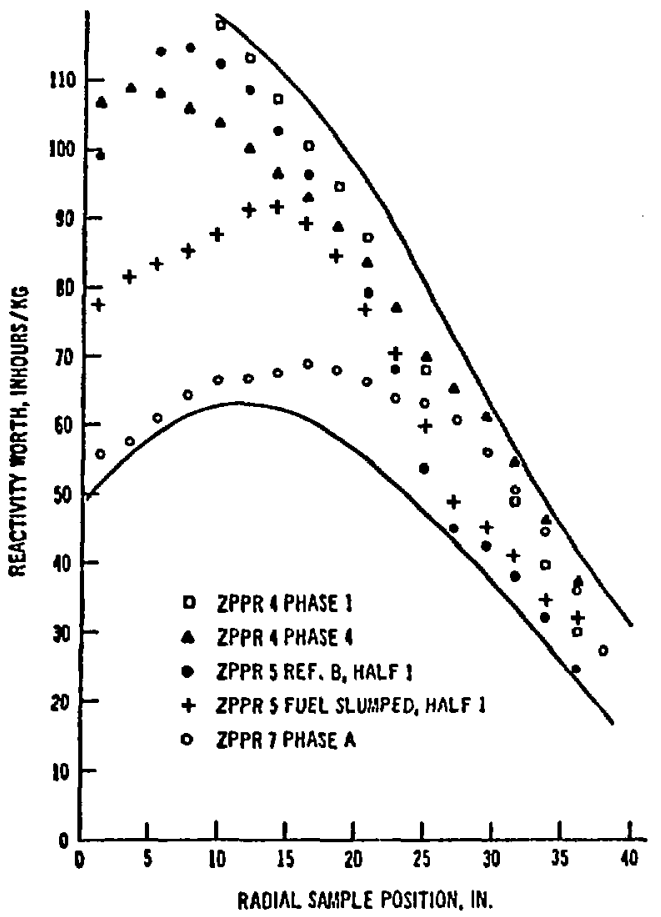

Fig. 6. Radial reactivity worth of $239 \mathrm{Pu}$ in ZPPR assemblies.

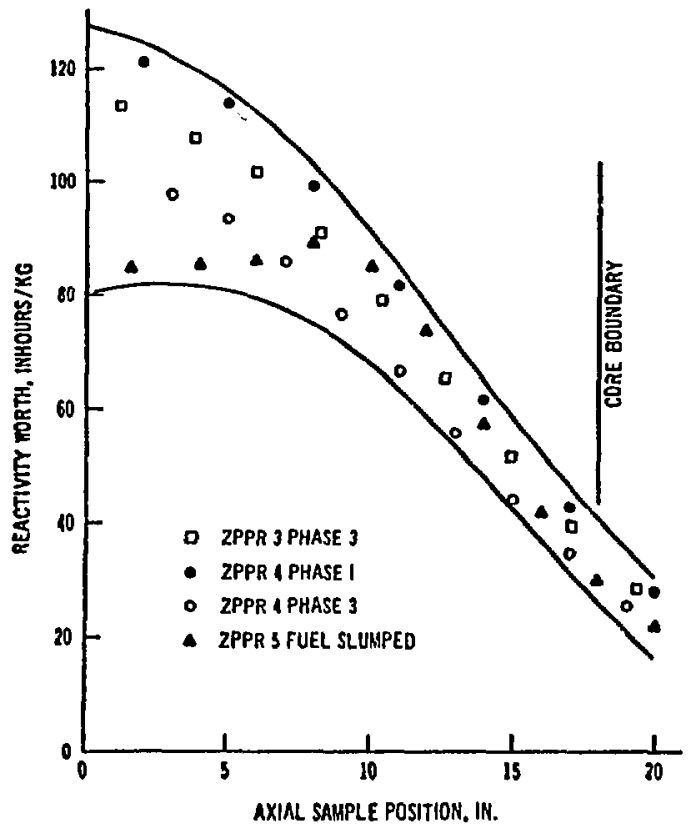

Fig. 7. Axial reactivity worth of $239 \mathrm{Pu}$ in ZPPR assemblies.

in column 3. Column 4 shows the ratio of the minimum-tocentral axial worth as obtained from the data in Fig. 7. The deduced corner worths (i.e., the product of columns 3 and 4 , assuming separability) are listed in column 5. They range from $5.2 \mathrm{Ih} / \mathrm{kg}$ in Assembly 5-Ref. B to $10.0 \mathrm{Ih} / \mathrm{kg}$ in the fuel slumped experiment (Assembly 5 ).

These worths are essentially point values at the core-axial blanket interface. Because actual plates will extend into regions of higher worth, a more useful number to evaluate safeguards effectiveness would be the minimum worth averaged over the length of a plate. These values are obtained by averaging the appropriate area of the axial worth profile, and are shown in Table II columns 6 and 7 for 1 -in. and 4-in. plates, 
${ }^{239} \mathrm{PU}$ WORTH DATA AND DETECTION SENSITIVITIES FOR ZPPR ASSEMBLIES

\begin{tabular}{|c|c|c|c|c|c|c|c|c|}
\hline $\begin{array}{c}\text { zPPR } \\
\text { Assembly } \\
\text { No. } \\
\end{array}$ & $\begin{array}{c}\text { Coro } \\
\text { Edge } \\
\text { Radius } \\
\text { (inches) } \\
\end{array}$ & $\begin{array}{r}239 \mathrm{Pu} \\
\text { Edge } \\
\text { Worth } \\
(\mathrm{Ih}) \\
\end{array}$ & $\begin{array}{c}\text { Min/Max } \\
\text { Axial } \\
\text { Worth } \\
\end{array}$ & $\begin{array}{l}239 \mathrm{Pu} \\
\text { Corner } \\
\text { Worths } \\
(\mathrm{Ih} / \mathrm{kg}) \\
\end{array}$ & $\begin{array}{c}\text { Minimum } \\
\text { Warth } \\
\text { 1- Sn. plate } \\
\text { (In/kg) } \\
\end{array}$ & 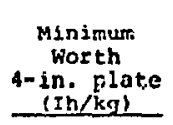 & $\begin{array}{l}\text { Detection } \\
\text { Sensitivity } \\
\text { l-in } 13 g_{\mathrm{Pu}}^{\text {late }} \\
\text { (kg }\end{array}$ & $\begin{array}{l}\text { Detection } \\
\text { Sensitivity } \\
4-i n_{2} \text { Pate } \\
\left(\mathrm{kg} 2 \text { Pu }_{\text {Pu }}\right.\end{array}$ \\
\hline 2 & 36.0 & 25.0 & - & & & & & \\
\hline $3-1 A$ & 40.0 & 22.0 & -- & & & & & \\
\hline $3-1.9$ & 36.0 & 24.6 & 0.31 & 7.6 & 8.2 & 9.8 & 0.37 & 0.31 \\
\hline $3-3$ & $-\infty$ & -- & 0.31 & & & & & \\
\hline $4-1$ & 37.0 & 25.0 & 0.30 & 7.5 & 8.0 & 9.6 & 0.37 & 0.31 \\
\hline $4-2$ & 37.0 & 21.0 & -- & & & & & \\
\hline $4-3$ & 37.0 & 26.7 & 0.30 & 8.0 & 8.5 & 10.2 & 0.35 & 0.29 \\
\hline $4-4$ & 37.0 & 31.9 & -- & & & & & \\
\hline 5 Ref. $\mathrm{B}^{\mathrm{a}}$ & 37.0 & 20.8 & 0.25 & 5.2 & 5.7 & 7.2 & 0.53 & 0.42 \\
\hline $5 \operatorname{Re} f . B^{b}$ & 37.0 & 20.8 & 0.29 & 6.0 & 6.5 & 8.0 & 0.46 & 0.38 \\
\hline $5 \mathrm{FS}^{\mathrm{J}}$ & 37.0 & 22.8 & 0.35 & 8.0 & B. $B$ & 11.1 & 0.34 & 0.27 \\
\hline $5 \mathrm{Fs}^{b}$ & 37.0 & 22.8 & 0.44 & 10.0 & 10.8 & 13.2 & 0.28 & 0.23 \\
\hline $6 \mathrm{EOC}$ & 37.0 & 25.8 & 0.24 & 6.2 & 6.8 & 8.6 & 0.14 & 0.35 \\
\hline $6 \mathrm{BOC}$ & 37.0 & 21.0 & $m$ & & & & & \\
\hline $7 \lambda$ & 39.4 & 21.8 & $-\infty$ & & & & & \\
\hline
\end{tabular}

respectively. The corresponding total amount of plutonium equivalent to a 3 -Ih reactivity loss is shown in columns 8 and 9 for 1- and 4-in. plates, respectively. Thus, in previous zPPR assemblies for which we have data, integral reactivity checks would detect removal of 0.28 to $0.53 \mathrm{~kg}$ of ${ }^{239} \mathrm{Pu}$ in the form of 1-in. plates (12-24 plates) and 0.23 to $0.42 \mathrm{~kg}$ of ${ }^{239} \mathrm{Pu}$ in 4-in. plates (2-4 plates). These detection sensitivities are for removal of plutonium from minimum worth regions. Smaller amounts removed from other parts of the core would be detectable. It should be noted that the 3-Ih limit represents a cumulative Iimit, in other words, the total amount of plutonium that could be removed before positive detection. It does not matter whether this amount of material was removed in a single theft or in a series of small diversions. These diversion sensitivities 
cannot be generalized to other fast critical assemblies; each case must be evaluated separately.

The above discussion of the use of reactivity measurements to detect diversion assumed only that plutonium fuel was removed from the assembly. There are, however, compensating methods that can increase reactivity and thereby mask fuel removal. These methods include adding moderating materials such as polyethylene, carbon, or beryllium to the ZPPR core, or moving plutonium from low-worth to high-worth regions. The ease of accomplishing such compensating reactivity changes will depend upon the knowledge and equipment available to the potential divertor. Significant compensating changes would most likely require that one or more criticality measurements be made to assure that the final reactivity is within 3 Ih of the reference value, and hence avoid detection. In domestic facilities, procedural controls and the two-man rule prohibit a single insider from performing such experiments. However, from the international viewpoint, it would be relatively simple for the operating facility to make the necessary changes. Thus, the effectiveness and confidence associated with integral reactivity measurements would be higher for domestic inspections than for international ones. In either case, the problems associated with integral reactivity checks should not negate their use, but should serve to emphasize the need for complementary and independent verification techniques and sampling plans.

Gross changes in core composition such as the addition of moderator or rearrangement of fuel will affect the neutron spectrum and other measurable reactor characteristics. Therefore, additional measurements could be performed to determine whether such changes have been made. Measurements of reactor parameters such as control-rod worth, reactivity worths of spectrumsensitive materials $\left(\mathrm{e} . \mathrm{g} .,{ }^{10} \mathrm{~B}\right.$ or $\left.{ }^{238} \mathrm{U}\right)$, reaction rates, spectral indices or neutron lifetime will yield information on gross core changes, even though the overall reactivity is maintained constant. The ease and sensitivity of these measurements 
will depend on characteristics of the specific facility under consideration. The IAEA is currently supporting a research program investigating these techniques at the spektr critical facility (small, highly enriched uranium fast assembly) at the Lenin Scientific Research Institute in Dimitrovgrad, USSR.20,21 Because of differences between Spektr and ZPPR, it is desirable to pursue a parallel investigation on $2 P P R-t y p e$ reactors.

\section{B. Autoradiography}

Autoradiography uses spontaneously emitted radiation (the 60$\mathrm{keV}$ gamma ray from $24 \mathrm{l}_{\mathrm{Am}}$ in the case of plutonilim) to expose $x$-ray film. ANL has developed and used this technique to verify plutonium plates in $2 P P R$ reactor drawers and storage containers. 22 Exposure time using Kodak AA film (industrial type $x$-ray film) is 10-15 min for reactor drawers and 30-45 $\mathrm{min}$ for vault canisters.

In the ZPPR assembly there is sufficient clearance between the contents of a drawer and the supporting matrix above it to insert a strip of prepackaged film without removing or handling the drawer itself. Figure 8 is a composite photographic print of several autoradiographs performed on fuel drawers inside the reactor.* The drawer shown in Fig. 8-A contains a single row of standard 0.25-in. thick IPPR fuel plates. Figure 8-B shows a drawer containing two rows of three plates each. In both cases the image of the fuel plate edges is clearly defined. Figure 8-C shows an autoradiograph of a drawer with no fuel in it, but with a drawer containing fuel in the matrix position above it. The absence of fuel is apparent. Although a very faint image of the fuel in the drawer above is visible, the steel matrix wall attenuates the gamma radiation so that a significant image is not produced.

* The autoradiograph figures included in this report are photographic copies of prints, which were in turn reproduced from the original $x$-rays. Because of reproduction losses in the various photographic steps, information in these figures is not as well defined as in the original film. Comments in the text are based on viewing the original film or the initial prints. 
A

B

C
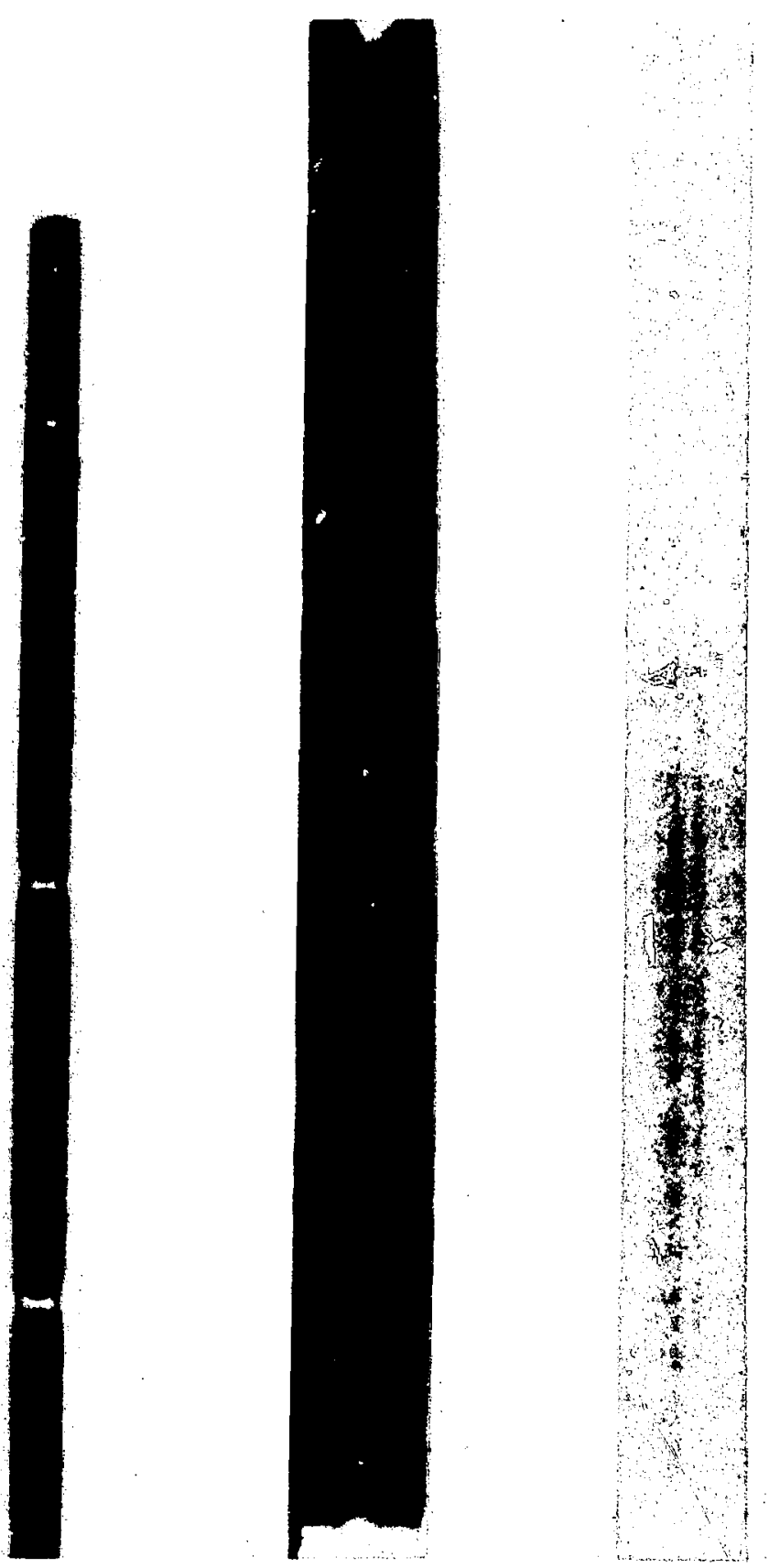

4

$4 \%$

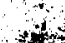
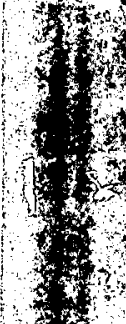

1 
For the verification of plutonium plates inside storage canisters, the film was placed beneath the aluminum canister without removing the canister from its vault position. Figure 9 shows a canister filled with 24 4-in. plates. Each plate image has a contribution from both direct and scattered radiation. The image of the four outside plates is lighter than the 20 interior plates because plates with only one neighbor have less scattered radiation contributing to their image density. Figure 10 shows a partially filled canister. The missing plate (third from the bottom, left side) is easily detected. Again the plate images on the outside are less dense. Figure 11 shows the results of replacing a fuel plate with a stainless steel "dummy" (center, right side). An image of the dummy plate is formed by scattered radiation from its neighbors. However, because the dummy plate emits no radiation, its image is less dense than that of a normal fuel plate. Note that the images of the plates adjacent to the dummy are also less dense than normal because there is no scattered radiation from the dummy. Thus, the neighbors have about the same image density as outside plates. The effect of substituting lead or uranium plates for fuel plates is the same as that shown for stainless steel. Substitution of low-z material such as aluminum will give a result more nearly resembling a vacancy. Although radiographs of canisters are not" quite as clear or as simple to interpret as radiographs of fuel drawers, a trained inspector should be able to determine the number of fuel plates in a canister.

The autoradiography techaique was used at the ZPPR facility in May 1977 to verify the entire inventory of $0.25-i n$. thick plutonium fuel plates. At that time the reactor was empty and all plates were stored in the vault. That exercise required five man-days to expose and process the $f i l m$, and one additional day to read and interpret the film.

Autoradiography provides a relatively simple and rapid method for identifying plutonium fuel plates. This is an attribute check (nonquantitative) for plutonium contenis, and requires a minimum of interference with normal operation. ANL 


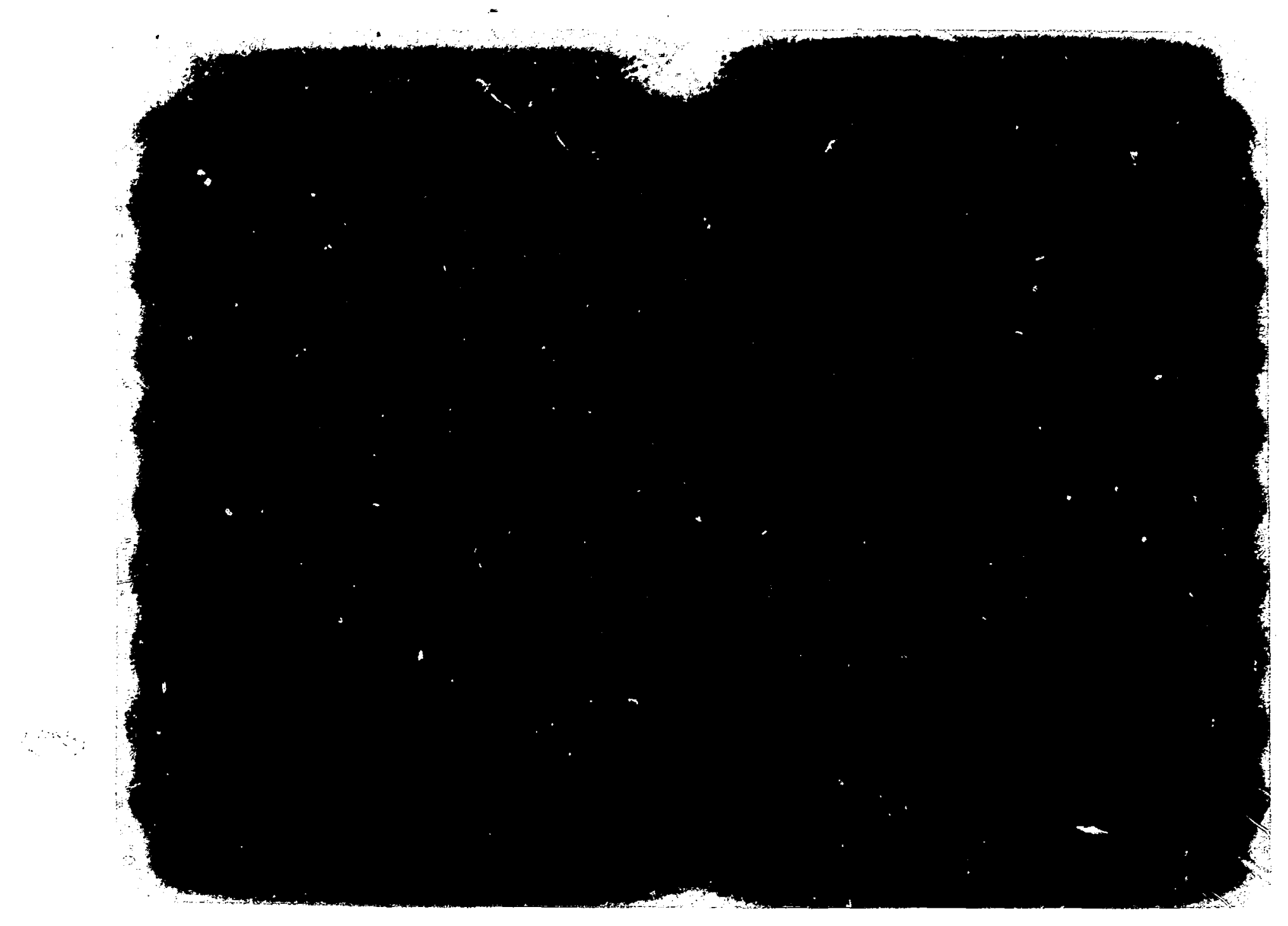

Fig. 9. Autoradiographic image of ZPPR storage canister containing 24 4-in. plutonium fuel plates. 


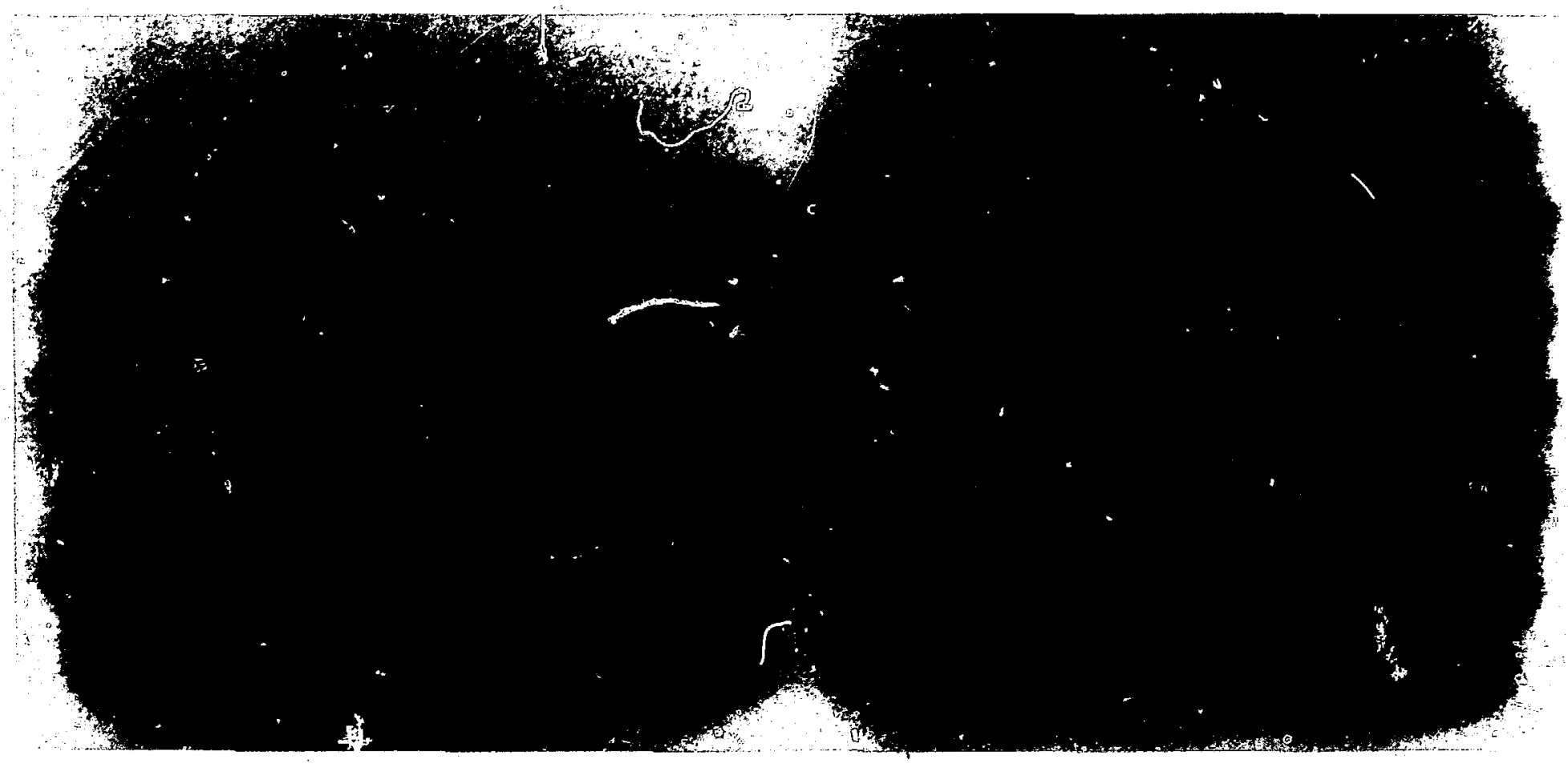

Fig. 10. Autoradiographic image of partially filled zPPR storage canister with missing plate (left side, third position from bottom). 


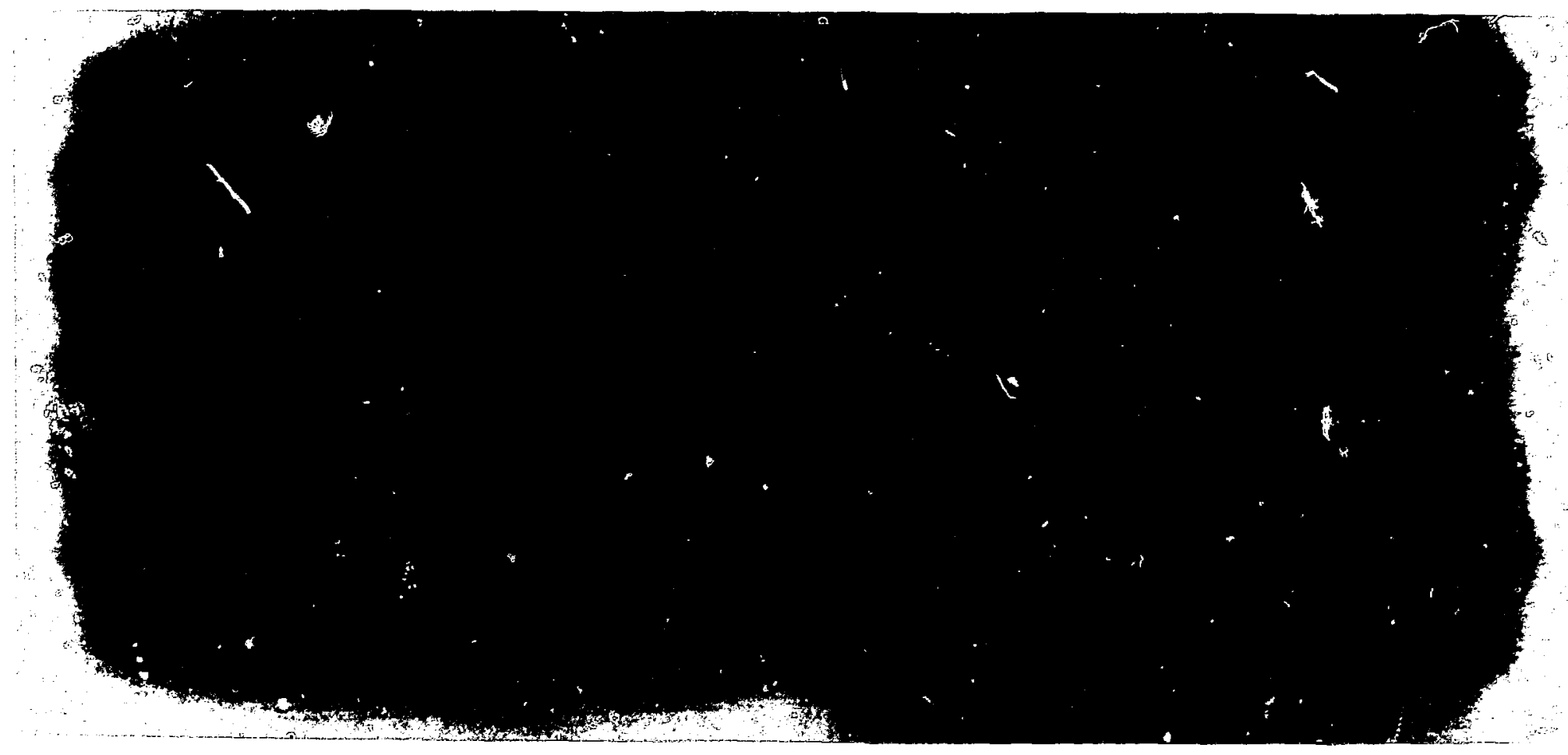

Fig. 11. Autoradiographic image of partially filled ZPPR storage canister with dummy solid stainless steel plate in center of right side. 
is developing this technique for use with enriched uranium. The exposure time required to form an image will be significantly greater. In addition to verifying the presence of uranium fuel, it may be possible to estimate the enrichment as well. A disadvantage of autoradiography is that it is essentially a surface effect, and, therefore, it does not verify the total plutonium content. Furthermore, it does not uniquely identify plutonium but only the presence of a correspondingly intense source of radiation.

\section{Nondestructive Assay (NDA)}

The NDA measurements discussed in this section are those that quantitatively determine the elemental and/or isotopic composition, concentration, or content of uranium or plutonium by detecting and recording neutrons or gamma rays emanating from the nuclear material being assayed. Over the past decade these techniques have been intensively developed and demonstrated under field conditions so that a variety of instruments exist that are sufficiently reliable and accurate to satisfy safeguards needs. In many cases the instruments are portable, or at least transportable. NDA methods are generally grouped into two major categories, passive and active. Passive assays use naturally orcurring gamma or neutron radiation as direct signatures of the nuclear materials being measured. Active assays first interrogate the material being studied with a neutron or gamma-ray source to produce fissions. and then measure the induced prompt or delayed radiation. In general, passive instruments are more compact and portable and suitable for use by inspectors, while active instruments tend to be bulkier and more appropriate for in-plant installations. Because plutonium isotopes emit measurable quantities of neutrons (directly from spontaneous fission of even isotopes) and gamma rays (primarily from ${ }^{239} \mathrm{Pu}$ and $241_{\mathrm{Pu}}$, the plutonium-bearing ZPPR fuel lends itself to passive assay techniques.

1. Neutron Measurements. Neutron assays may record the gross (or total) neutron counts or the time-correlated (or 
coincident) neutron counts. In addition to neutrons emitted directly in spontaneous fissions (usually by $240 \mathrm{Pu}$ ), other neutrons may be generated indirectly by $(\alpha, n)$ reactions of strong emitters on light nuclei. Gross measurements count all neutrons produced including those from spontaneous fissions, $(\alpha, n)$, and background reactions. Coincidence counting separates the fission events from the random background and $(\alpha, n)$ sources. Gross neutron counting serves as a suitable technique in cases where the material to be assayed is well characterized, emits relatively few $(\alpha, \eta)$ neutrons, and the barkground source is constant. If these conditions are not met, or if the material to be assayed produces unknown or varying amcunts of $(\alpha, n)$ neutrons, then gross counting becomes less reliable and coincidence counting may be necessary. The ZPPR plates are very well characterized with respect to both geometry and composition and contain only trace amounts of light elements. Therefore, if the background can be maintained constant, gross counting of these plates either singly or collectively may be acceptable. However, fuel plates made from a Pu-Al alloy such as those used at FCA, will produce a relatively strong $(\alpha, n)$ source and probably require coincidence counting for accurate assays.

High efficiency, transportable neutron coincidence counting equipment developed and built at the Los Alamos Scientific Laboratory has been used by the IAEA at the FCA facility. Since neutron counting measures the $240 \mathrm{Pu}$ content, supplementary gamma measurements of isotopic ratios are needed if an inderendent verification of fissile content is required. Figure 12 shows a mockup drawer being assayed using a combination of neutron coincidence counting and gamma-ray isotopic analysis. The drawer is inserted into a high-level neutron coincidence counter (HLNCC) placed on its side. Gamma-ray data are accumulated simultaneously using a collimated, high-resolution, intrinsic germanium detector. A two-position measurement technique is being studied to give uniform assay weight to the plutonium regardless of its axial position in the drawer. 
2. Gamma Measuren:ents. In addition to yielding isotopic ratios, gamma-ray spectroscopy may also be used to verify total fissile content. Shortly after the 2PPR plates were fabricated, an automated, computer controlled gamma-ray measurement system was used to verify the content of each fuel plate individually. 23

We are currently investigating the use of gamma-ray spectroscopy to verify the contents of an entice drawer. In these measurements the detector views the top of the drawer as in Fig. 12, but the detector/drawer separation is

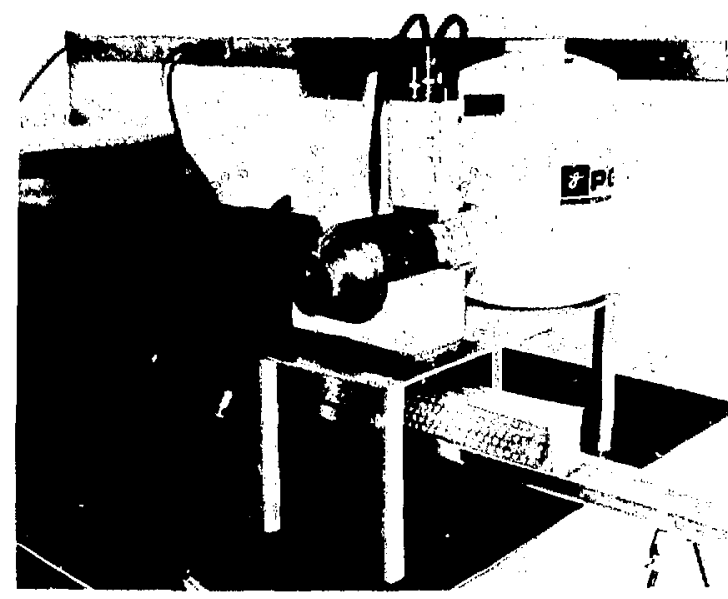

Fig. 12. Measurement setup for a ZPPR drawer showing the HLNCC for neutron counting and the IAEA intrinsic germanium detector with its collimator for measurement of plutonium gamma-ray line ratios. sufficiently large so that the response is relatively flat along the active fuel length. An advantage of gamma spectroscopy is that the presence of ${ }^{239} \mathrm{Pu}$ is directly and unambiguously verified. However, because of seif attenuation of the fgarnma rays, only material near the upper edge of the plates is/measured, as opposed to the entire fuel volume that is measured with the more penetrating neutrons.

NDA techniques using neutrons and/or gamma-ray measurements may be used to verify fuel plates either singly or collectively. The detection sensitivity to missing material. and the corresponding counting times should be determined for these techniques in order to evaluate their effectiveness as part of an overall safeguards system. 
v. CONCEPT DEVELOPMENT: THE SAFEGUARDS STUDY

This report is the first milestone in a study of advanced safeguards for critical facilities. The next part of the study will concentrate on developing the techniques outlined in Secs. III and IV for rapid and continuous verification of reactor and vault inventories. The results will be applicable to both domestic and international safeguards for critical facilities.

From the international safeguards viewpoint, a continuous presence of IAEA inspection may be required at large critical facilities. If this is the case, instrumentation used by the inspectors for verification measurements could remain in place at the facility, along with appropriate standards maintained under tamper-proof seal. Plans for continuous sampling of the reactor inventory could be designed and implemented by the IAEA with the cooperation of the facility operator. Portable instruments for gamma-ray and neutron measurements have already been developed at LASL and supplied to the IAEA. Inventory verification based on measurements of reactivity may require that additional portable instrumentation be developed. Techniques already developed for autoradiography measurements should be transferred to the IAEA as soon as possible.

Appearance of a recommendation in this chapter does not imply that the development task will be performed during the study. Some concepts may be modified or abandoned as a result of further review and discussions with ANL personnel. In many cases the development effort is outside the scope of the planned study and will require additional funding and/or priority guidance from DOE/SS.

\section{A. Development of Measurement Concepts}

Several measurement techniques are identified in sec. IV that will be useful in verifying the SNM inventory at critical assembly facilities. In most cases further development is needed to quantify the effectiveness and reliability of these techniques for application to specific facilities. Our 
recommendations for further investigations in this area are given below.

1. Integral Reactivity Measurements. The effectiveness of integral reactivity measurements as a means of verifying the fuel inventory inside the reactor was estimated based on data obtained from previous ZPPR assemblies. To better determine the diversion detection sensitivity and the reliability of this technique, the following investigations should be performed:

A reference configuration should be established at ZPPR and its reactivity measured.

- The reactivity should be consistently remeasured as a function of time to accurately determine the reactivity loss due to the decay of fissile ${ }^{241} \mathrm{Pu}$.

- The reactivity worth of ZPPR fuel plates should be measured in various parts of the reactor, with special emphasis on the outermost regions where the worth is lowest.

- Calculations should be performed to investigate the use of compensating reactivity changes to mask fuel removal, and the effect of such changes on the reactor characteristics. The feasibility of detecting compensating reactivity changes by measurement of reactor parameters should be investigated. Parameters of interest include:

- neutron spectrum

- control rod worth

- reactivity worth of spectrum-sensitive materials, e.g., $10_{B}$ or ${ }^{238_{U}}$

- reaction rates

- spectral indices

- neutron lifetime.

- Because IAEA inspectors must perform independent verifications, they must either use their own instruments or verify the performance of any in-plant instruments they wish to use. If reactivity measurements are shown to be a useful technique for IAEA 
instruments they wish to use. If reactivity measurements are shown to be a useful technique for IAEA inspections, portable instruments to measure reactivity should be developed. These instruments need not be as accurate as the facility's instruments because they will primarily serve to check and verify the behavior of in-plant instruments that can then be used, with confidence, to accumulate accurate data.

- It would be useful for IAEA inspectors to be able to verify gross amounts of SNM in a critical assembly without requiring the operator to bring the halves together and perform an integral reactivity measurement. Use of source multiplication, variance-to-mean, or flux measuring techniques for this purpose should be investigated.

- The use of irradiated foils to check the integrated power during the approach to criticality should be investigated.

2. Autoradiography. The use of autoradiography to verify the presence of plutonium fuel plates has been successfully demonstrated and no further developmental effort is necessary. ANL is developing this technique for detection of uranium fuel. This effort should be monitored because it could have useful applications at critical facilities.

3. NDA Measurements. The effectiveness and usefulness of NDA techniques for verifying SNM depends upon the counting times required and the corresponding sensitivity to missing material. This information should be obtained for various NDA techniques, both neutron and gamma, applied to reactor drawers and storage canisters.

\section{B. Development of Accounting Concepts}

A combination of periodic measurements of integral reactivity and continuous sampling of fuel drawers using NDA measurements is proposed for timely verification of the reactor inventory. Each measurement technique is sensitive to different 
The effectiveness of any particular strategy is a complicated function of many factors including operating procedures and practical constraints. For reliability and credibility, the evaluation and selection process depends on computerized modeling and simulation methodology coupled with powerful decision analysis tools. ${ }^{3-5}$ Our experience has shown that a specific facilily must be modeled to maintain the necessary contact with reality; in this case, ZPPR is the reference facility. Based on consultations with ZPPR personnel, operations concerning use and movement of SNM at the ZPPR facility will be modeled. Accountability measurement techniques (based on the best available estimates of performance and sensitivity) and statistical sampling plans will be applied to the simulated SNM inventories. Alternative accounting and diversion strategies will be evaluated and compared using analysis tools adapted for this purpose. Recommendations will be made on the basis of these comparisons.

\section{ACKNOWLEDGMENT}

We gratefully acknowledge the cooperation of the staff at Argonne National Laboratory East and West. We particularly thank P. Amundson, S. Brumbach, R. Forrester, R. Perry, G. Rusch, M. Ryan, and F. Thalgott for supplying us with important information used in this study. 
1. H. Lawroski, "Zero Power Plutonium Reactor Facility," Nuclear News (February 1968), 47-49.

2. "Conceptual Design of a Safeguards System for ZPPR," Draft Report prepared by Systems Studies and Engineering Division 1754, Sardia Laboratories, Albuquerque, NM, (September 2, 1977).

3. J. P. Shipley, D. D. Cobb, R. J. Dietz, M. L. Evans, E. p. Schelonka, D. B. Smith, and R. B. Walton, "Coordinated Safeguards for Materials Management in a Mixed-oxide Fuel Facility," Los Alanos Scientific Laboratory report LA-6536 (February 1977).

4. E. A. Hakkila, D. D. Cobb, H. A. Dayem, R. J. Dietz, E. A. Kern, E. P. Schelonka, J. P. Shipley, D. B. Smith, R. H. Augustson, and J. W. Barnes, "Coordinated Safeguards for Materials Management in a Fuel Reprocessing Plant," Los Alamos Scientific Laboratory report LA-688. (October 1977).

5. H. A. Dayem, D. F. Bowersox, D. D. Cobb, R. J. Dietz, E. A. Hakkila, E. A. Kern, J. P. Shipley, and D. B. Smith, "Coordinated Safeguards for Materials Management in a Conversion Facility," Los Alamos Scientific Laboratory report LA-701l (to be published).

6. Code of Federal Regulations (Title 10, Part 70), office of the Federal Register, National Archives and Records Service, General Services Administration, Washington, DC.

7. ERDA Manual, Part 7400 (Materials Management), USERDA, Washington, DC.

8. "The Structure and Content of Agreements between the Agency and States Required in Connection with the Treaty on the Non-Proliferation of Nuclear Weapons," International Atomic Energy Agency, INFCIRC/153 (June 1972).

9. J. E. Lovett, "Concepts of Real Time and Semi-Real-Time Material Control," Nucl. Mater. Manage. IV(III), 24-33 (1975).

10. G. R. Keepin and W. J. Maraman, "Nondestructive Assay Technology and In-Plant Dynamic Materials Control--DYMAC," in Safeguarding Nuclear Materials, Proc. Symp., Vienna, 1975 (International Atomic Energy Agency, Vienna, 1976) paper IAEA-SM-201/32, pp. 305-320.

11. J.M. de Montmollin and R. B. Walton, "The Design of Integrated Safeguards Systems for Nuclear Facilities," Nucl. Mater. Manage. V(III), 317-332 (1976). 
12. R. H. Augustson, "Development of In-Plant Real-Time Materials Control: The DYMAC Program," Nucl. Mater. Manage. V(III), 302-316 (1976).

13. J. P. Shipley, "Decision Analysis for Nuclear Materials Accounting," Vol. II, App. E, Los Alamos Scientific Laboratory report LA-6881 (October 1977); see Ref. 4.

14. D. H. Pike and G. W. Morrison, "A New Approach to Safeguards Accounting," paper presented at the $18 \mathrm{th}$ Annual Meeting of the Inst. of Nucl. Mater. Manage. (June 1977); to be published in the Proceedings.

15. D. D. Cobb, D. B. Smith, and J. P. Shipley, "Cumulative Sum Charts in Safeguarding Special Nuclear Materials," submitted to Technometrics (December 1976).

16. D. D. Cobb and D. B. Smith, "Modeling and Simulation in the Design and Evaluation of Conceptual. Safeguards Systems," paper presented at the 18th Annual Meeting of the Inst. of Nucl. Mater. Manage. (June 1977); to be published in the Proceedings.

17. A. J. Duncan, Quality Control and Industrial Statistics, Third Edition (Richard D. Irwin, Inc., 1965).

18. J. L. Jaech, "Statistical Methods in Nuclear Material Control," TID-26298, US Government Printing Office, Washington, DC (1973).

19. R. G. Mattock, R. E. Kaiser, and J. M. Gasidlo, "Reactivity Effects in Critical Facilities Due to Fissile Isotope Decay," 1969 Winter Meeting of the American Nuclear Society, November 1969.

20. V. M. Gryazev, "Development of Procedures and Techniques for Verifying the Quantity and Composition of Nuclear Materials at the Spektr Fast and Thermal Neutron Critical Facility." Translated from Russian 74-8355 (1974).

21. V. M. Gryazev, "Experiments with a Nuclear Materials Accounting and Control system on the Spektr Fast-Thermal Critical Assembly," Translated from Russian 76-1726 (1976).

22. Personal communication, S. B. Brumbach, Argonne National Laboratory, June 1977.

23. R. B. Perry, R. W. Brandenburg, and N. S. Beyer, "Nondestructive Assay of ZPPR Fuel," Proceedings of the Ninth Annual Meeting of the Inst. of Nucl. Mater. Manage., p. 205 (May 1968). 